\title{
Research on Optimization of Public Service Facilities Land Efficiency in Changchun City Based on Compact City
}

\author{
Lv Jing, Yan Tianjiao* \\ School of Architecture and Urban Planning, Jilin Jianzhu University, Changchun, China \\ Email address: \\ 627274324@qq.com (Lv Jing), 984696184@qq.com (Yan Tianjiao) \\ ${ }^{*}$ Corresponding author
}

To cite this article:

Lv Jing, Yan Tianjiao. Research on Optimization of Public Service Facilities Land Efficiency in Changchun City Based on Compact City. American Journal of Civil Engineering. Vol. 6, No. 4, 2018, pp. 123-133. doi: 10.11648/j.ajce.20180604.13

Received: August 20, 2018; Accepted: September 14, 2018; Published: October 18, 2018

\begin{abstract}
With the continuous development of the social economy, the city has a chaotic image of unwarranted expansion, so the proposal of compact cities and stock planning has been very important. Land for public service facilities is a major component of urban functional land, so it can be used to reflect the compactness of urban land. Based on the background of compact city, this paper analyzed the service efficiency of public service facilities land in Changchun City, including land for educational and cultural facilities, sports facilities, medical and health facilities and social welfare facilities. Through GIS and other technical means to process the data, and comprehensive analysis of the number of facilities, spatial distribution and accessibility analysis, the results of spatial allocation were obtained. In order to consider the behavioral factors of human beings, these results were divided into suppliers, suppliers and demanders for comparative analysis, and the influencing factors and their interrelationships leading to these results were obtained. At the same time, this gave specific suggestions on regional control, spatial structure compactness and spatial element allocation from the macro, meso and micro levels. Furthermore, it will give the relevant planning department measures and recommendations about optimizing the space efficiency of land use for public service facilities.
\end{abstract}

Keywords: Compact City, Land for Public Service Facilities, Efficiency, Optimization Strategy, Changchun

\section{Introduction}

Since the 19th century, western countries have experienced periods of various problems such as urban disorder expansion and environmental degradation in urban construction. Early compact cities promoted the urban development model of high density and land use in the Middle Ages in Europe [1, 2] With the advancement of sustainable development ideas, in order to reduce the energy consumption of cars, compact cities have proposed travel modes based on walking, bicycles and public transportation [3]. High density, land use mix and promotion of walking, cycling and public traffic travel are three important features of compact cities. In recent years, compact cities have become one of the reference models for sustainable urban development in China, especially in terms of land use. The concept of compact urban land use from HongMin included high-intensity use of land, moderate mixed use of land functions, and coupling with traffic and decentralized land use patterns [4]; LiLin proposed that compact cities provide more urban space with less land and carry higher quality urban life [5]; WeiYaping used standard section comparison model to describe the relationship between "compact urban development" and "land use performance" [6]. The high-intensity and high-density development of land has been recognized but the city as an organic whole, the spatial structure within the city has an important impact on the realization of urban function and efficiency. And the research in the past decade has put emphasis on the macro level, the discussion of high density ignores the spatial structure of the city and the relationship with land use efficiency. Since Chinese urban development stage and characteristics are different from those of western developed countries, whether Chinese cities should continue the compact meaning of "high density, mixed land use and public transportation", it is necessary to explore the compactness of urban interior space and the efficiency of urban land use. The relationship is conducive to clarifying 
the actual connotation and significance of compact cities in the development of Chinese cities.

Foreign research on public facilities land is divided into three aspects, including location, configuration model and spatial optimization model. In the late 1960 s, the location research of public service facilities began to appear [7], and focused on the equalization of land use for public facilities $[8$ 9]. In the mid-to-late 1970 s, the social embedded process analysis method was more in line with social reality [10]. Since the 1980s, GIS technology has been introduced into the study of public service facilities [11, 12], and has become increasingly popular. Location fairness and spatial equity have received much attention, and the concept and method of accessibility have been widely used [13]. At the same time, research on public service facilities has shifted to specific and microscopic, such as the distribution and utilization of facilities in hospitals, parks, and education facilities. Since the 1990s, accessibility is still an important indicator to measure the rationality of the spatial layout of public service facilities, but scholars have begun to pay attention to the needs and social equity of public service facilities in different groups, different strata, and different regions [14, 15].

There is no clear definition of "land use efficiency". The currently concept used refers to the degree of distribution of limited resources based on population proposed by LiWen et al. (2010). Space efficiency in this paper was based on the combination of spatial accessibility and matching of population distribution, including the quantity and quality of services. In the context of a compact city, consideration of people is particularly important. It is necessary to examine the demand side, that is, the situation in which residents obtain public service resources. At the same time, it analyzed the service capabilities of the supply side and rationally configured the two to achieve the maximize efficiency. Encouraging residents to walk and improve the allocation of public service facilities is also one of the compact city requirements.

\section{Research Scope and Research Methods}

\subsection{Research Scope}

The scope of this paper is the downtown area of Changchun, which achieves fairness in resource allocation by communicating with elements in other regions (Figure 1). It is the growth pole of Changchun, with strong appeal, radiation and comprehensive service capabilities.

The downtown area of Changchun includes 9 administrative districts: Nanguan District, Chaoyang District, Kuancheng District, Erdao District, Lvyuan District, Economic Development Zone, High-tech Development Zone, Automobile Development Zone, Jingyue Economic Development Zone, and total area is about $610 \mathrm{~km}^{2}$.

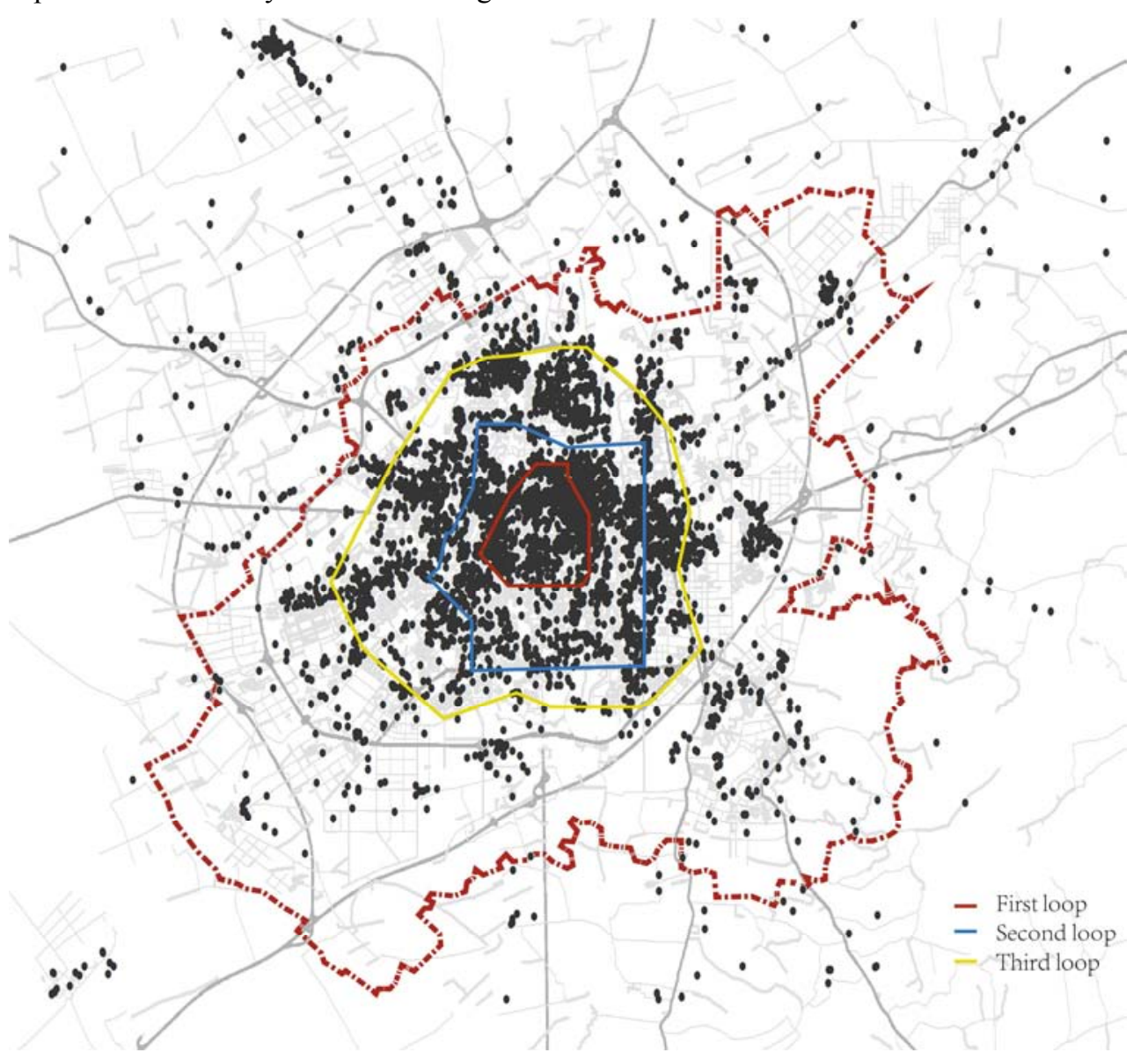

Figure 1. Area of research. 


\subsection{Research Methods}

\subsubsection{Data Acquisition and Processing}

The source of data included captured 2018 Point Of Interest (POI) and Changchun City and District Yearbook. According to the "Urban Land Classification and Planning and Construction Land Use Standards (GB 50173-2011)", the land for public service facilities is divided into six categories: land for administrative office, land for cultural facilities, land for education and scientific research, sports land, medical and health land, and commercial service land. Based on the background of compact cities, this paper focused on four types: educational and cultural service facilities, sports facilities, medical facilities and social welfare facilities.

\subsubsection{Data Analysis Method}

The analysis of the data was through three levels: quantity distribution, spatial distribution and spatial configuration. The distribution of the quantity can be obtained by statistical methods and the spatial distribution can be visualized by nuclear density analysis. The space allocation problem is essentially the accessibility of the facility. Therefore, the spatial distribution and the accessibility can be combined to evaluate the the level of efficiency.

(1) Kernel Density Analysis

Kernel Density Analysis is used to calculate the density of features in their surrounding neighborhoods and it can reflect the spatial distribution of point features and line features, where the spatial aggregation of POI can be visualized. It gives more weight to the point closer to the distance, which can fully reflect the law of distance attenuation of spatial diffusion. Its formula is as follows:

$$
F(x)=\frac{1}{n h^{d}} \sum_{i=1}^{n} K\left(\frac{x-x_{i}}{h}\right)
$$

Where: $\mathrm{K}(\mathrm{x})$ is the kernel density formula; $\mathrm{h}$ is the thres hold; $\mathrm{n}$ is the number of points; $\mathrm{d}$ is the dimension of the data.

(2) Accessibility Analysis

In the accessibility analysis, it is commonly used based on GIS to represent the space resistance by the shortest traffic distance or the shortest travel arrival time, so as to obtain the spatial accessibility analysis:

$$
A_{i j}=\sum_{i=1}^{n} f\left(D_{i j}\right)
$$

Where: $A_{i j}$ is the reachability index; $i$ is the demand point of the residents; $n$ is the number of demand; $D_{i j}$ is the space resistance.

Then, considering the attractiveness of the facility itself on the basis of accessibility, Hansen WG (1959) and Handy proposed an attractive model $[16,17,18]$, which will attract urban public service facilities, space resistance and users combined, this article used the gravitational reachable model as following formula:

$$
A_{i j}=\sum_{i=1}^{n} \frac{S_{j}}{D_{i j}^{\beta}}
$$

Where: $\mathrm{S}_{\mathrm{j}}$ is the attraction of point $\mathrm{j} ; \beta$ is the distance attenuation coefficient, which is taken as 2 in this paper.

\section{Changchun City Public Service Facilities Space Matching}

The spatial matching of public service facilities in Changchun City is analyzed in three aspects, including the classification, the spatial distribution and the spatial configuration of facilities. On the basis of studying the number, scale and area of each type of facilities, considering the space allocation problem caused by the service radius and accessibility, this paper added the elements of the spatial layout of compact city construction.

\subsection{The Relationship with Mixed Function}

The total of 5,287 POIs of 4 types of public service facilities in the downtown area of Changchun in 2018 were captured. The proportion of various types of facilities was shown in Figure 2. There were 1,285 POIs in educational and cultural facilities, which were composed of educational facilities and cultural facilities. Educational facilities include kindergartens, primary schools, secondary schools (junior high schools, high schools, full secondary schools) and other educational facilities. Cultural facilities include activity centers, public libraries, museums, art galleries and more. In sports facilities, the number of POI in various parks and plazas was 146, and 269 various types of sports venues. Health care facilities include clinics and hospitals with a total catch of 3,380. Social welfare facilities mainly include nursing homes and old-age service centers, and a total of 184 POI data were collected.

The number of POI was calculated by administrative divisions. According to the traditional division method, it is divided into five traditional areas: Chaoyang, Erdao, Kuancheng, Lvyuan and Nanguan districts. Lvyuan District includes the current Auto Development Zone, Chaoyang District includes High-tech South District, Nanguan District includes Jingyue Development Zone, and Erdao District includes Economic Development Zone and High-tech North District. When counting the number of different types of facilities, the weighted analysis of the proportion of various facilities was included, and the degree of functional aggregation in different regions can be divided into five levels, as shown in Figure 2. The educational and cultural facilities in each district have a large proportion of kindergartens, and there are fewer primary and secondary schools and cultural facilities. The number of nursing homes in social welfare facilities accounts for a large proportion, 
and the welfare centers for communities account for a small proportion; the proportion of clinics and specialist hospitals in medical and health facilities is relatively large, and the proportion of comprehensive hospitals is relatively small; parks in sports facilities are relatively small and unbalanced, especially in Chaoyang District and Nanguan District. On the whole, the number of medical and health facilities is the largest, followed by educational and cultural facilities, sports facilities and social welfare facilities are almost the same and the number is small.

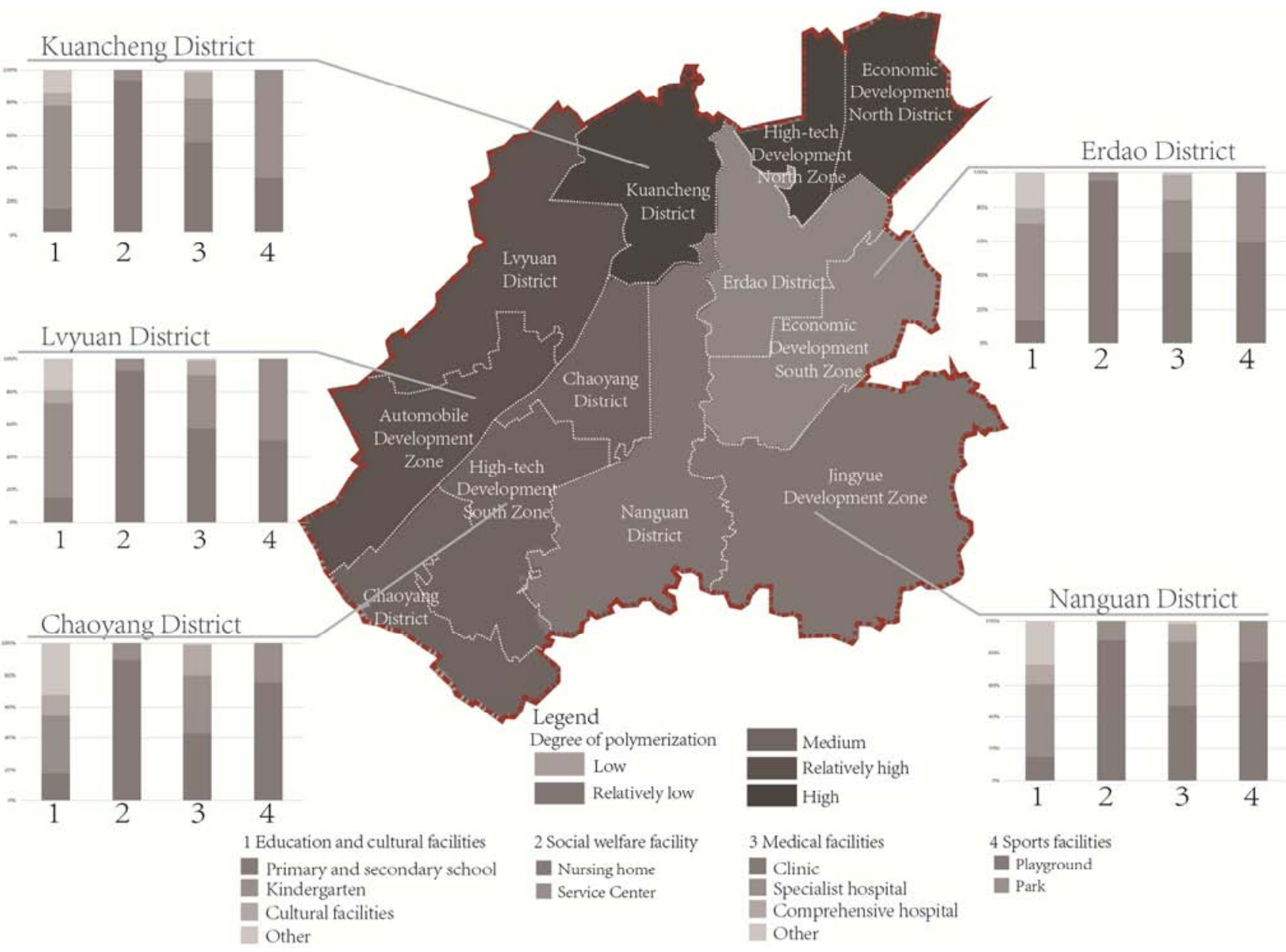

The-number-of·facilities· in d different-administrative-regions.

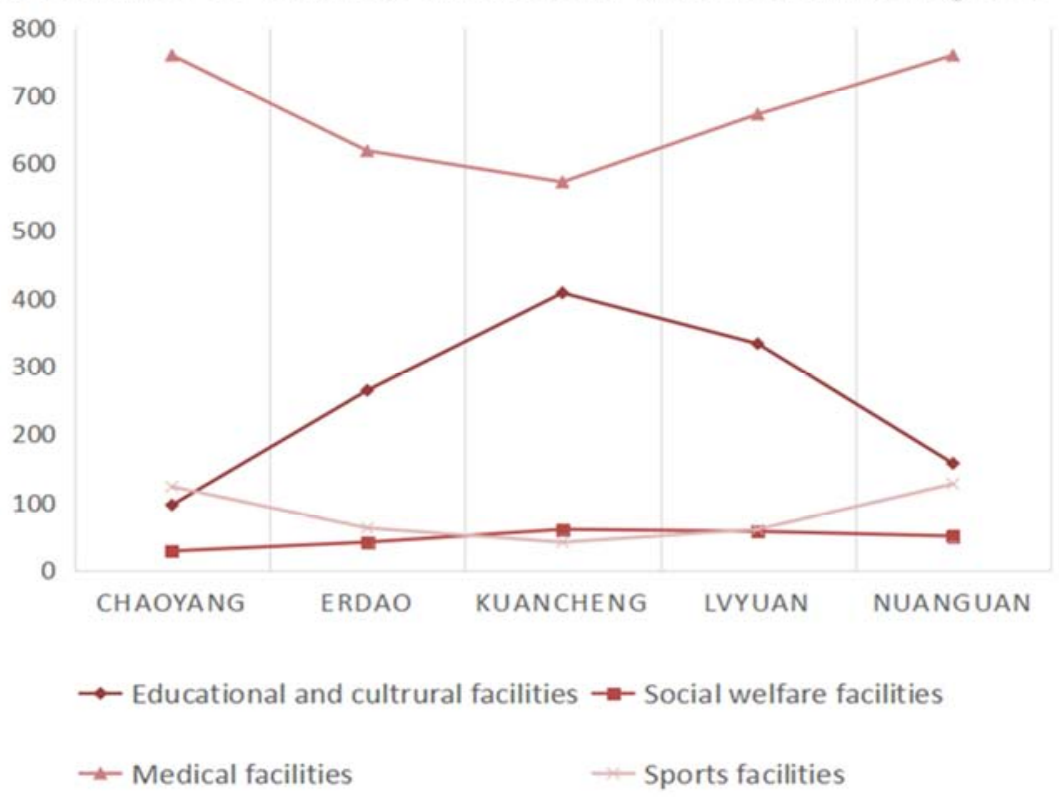

Figure 2. The number and composition of service facilities in each district of Changchun. 


\subsection{The Relationship with Spatial Distribution}

Based on the nuclear density analysis function in GIS, Density Type selected Kernel and used the Jenks natural segmentation to classify it into five levels to obtain the spatial distribution density of various public service facilities. It can be seen from the figure 3 that the educational and cultural service facilities are distributed in the northern part of the central area, and the overall distribution is uneven; the sports facilities are mainly distributed along the Renmin
Road, and the highest concentration is gathered near the parks such as Shengli Park, Animal and Plant Park and Nanhu Park. The medical service facilities gathered in the vicinity of Chongqing Road. Because there are large medical facilities such as Renmin Hospital, Maternity Hospital, Children's Hospital and Jilin University Second Hospital near Chongqing Road. The overall distribution is relatively balanced. Social welfare facilities are scattered and have the highest concentration near the North Lake.

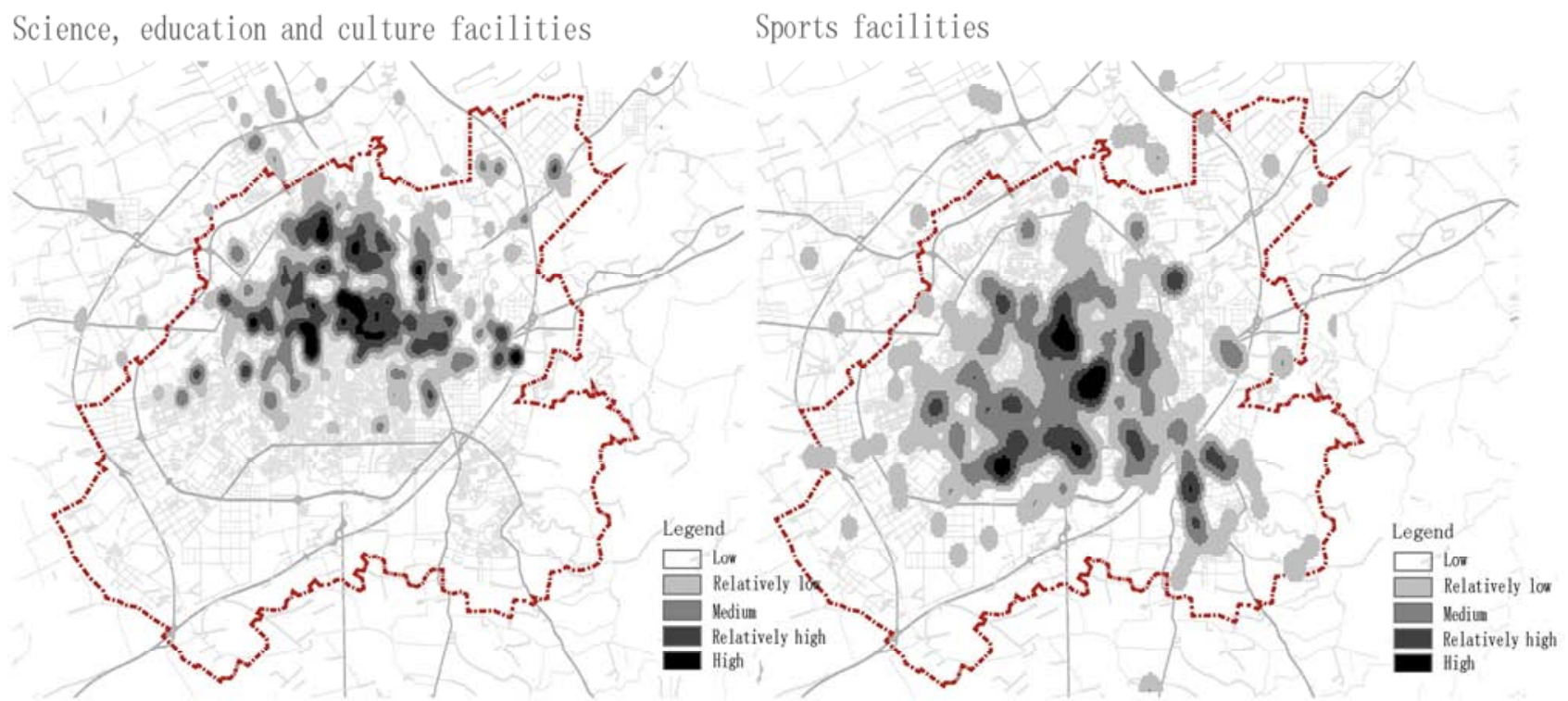

Medical facilities

Social welfare facilities

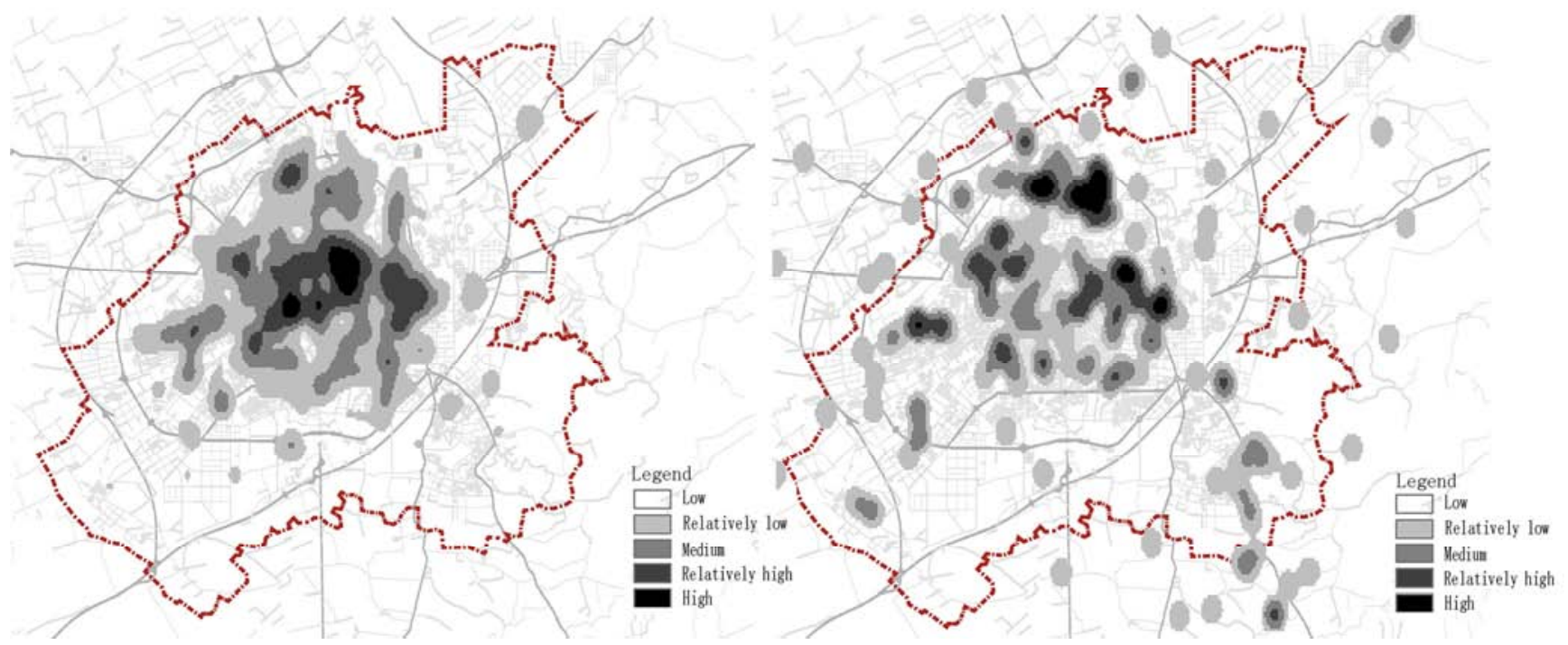

Figure 3. Nuclear density analysis of public service facilities.

\subsection{The Relationship with Traffic Accessibility}

Traffic accessibility directly determines human behavior. Road density is one of the important indicators for evaluating the degree of road aggregation. This paper divided the downtown area of Changchun into a grid of $100 \mathrm{~m} * 100 \mathrm{~m}$ by GIS, and the length of the road in each unit is calculated. The following figure is obtained, and the road density distribution can be clearly found. The high road density indicates that the area is highly connected and has high accessibility within walking distance, which encourages people to exercise. The sports facilities in the Jingyue Development Zone have the highest accessibility, followed by the Economic Development North Zone; the medical facilities are the most 
accessible in the old city center, followed by the Automobile Development Zone; the accessibility of cultural facilities reaches the highest in the vicinity of the Satellite Square. Followed by the Auto City and Jingyue University City. The most important primary and secondary schools in educational facilities have a great influence on their distribution. The service radius of primary and secondary schools is 500 meters and 1000 meters respectively. The coverage of the

Changchun downtown area road network density
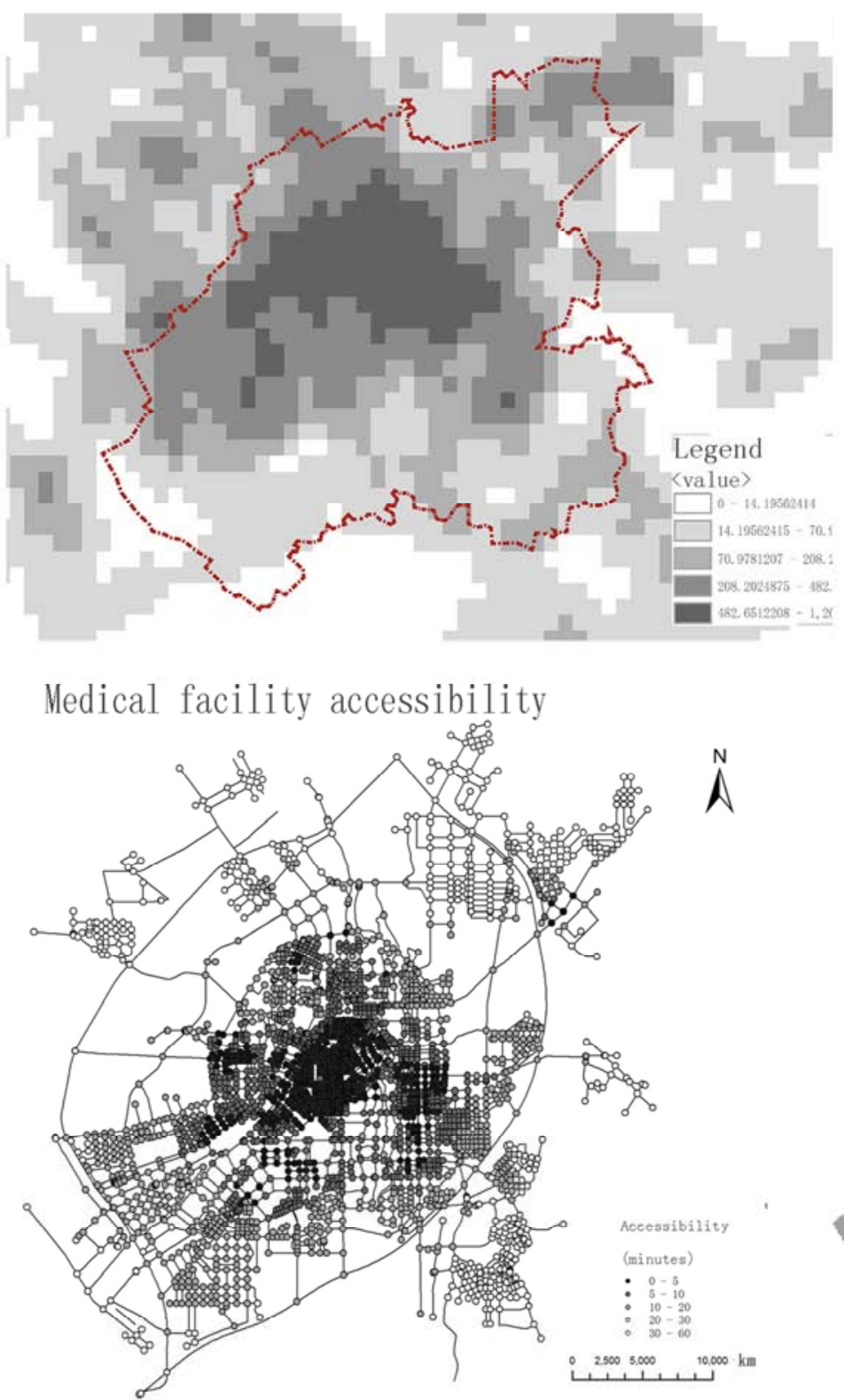

service area is divided into 6 levels. The ratio of the coverage of primary schools at a radius of 500 meters and the proportion of secondary school coverage at a radius of 1000 meters are calculated at each level as shown in Figure 5. In general, the majority of the two are concentrated in areas with coverage of 1 and 2, and service efficiency needs to be improved, while secondary coverage is slightly higher than that of primary schools.

\section{Sports facility accessibility}

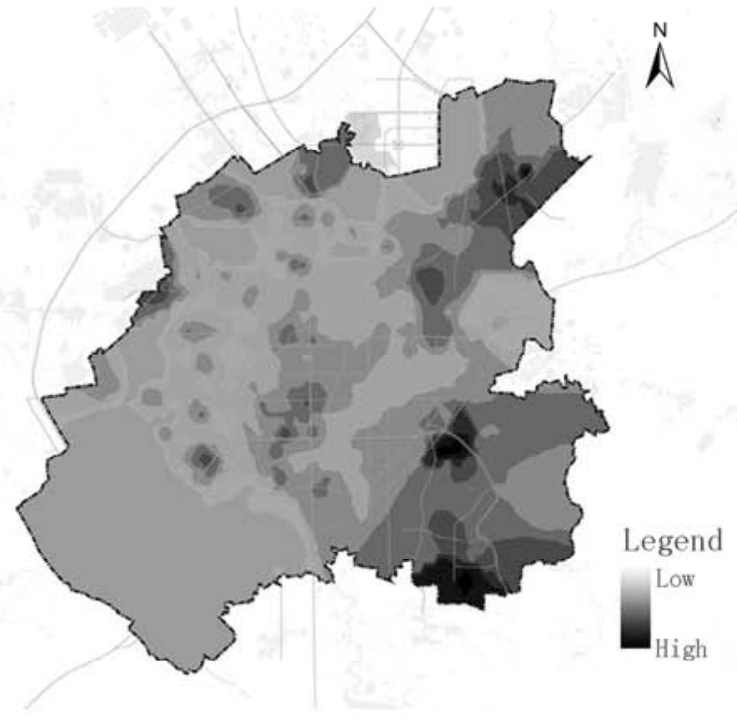

Cultural facility accessibility

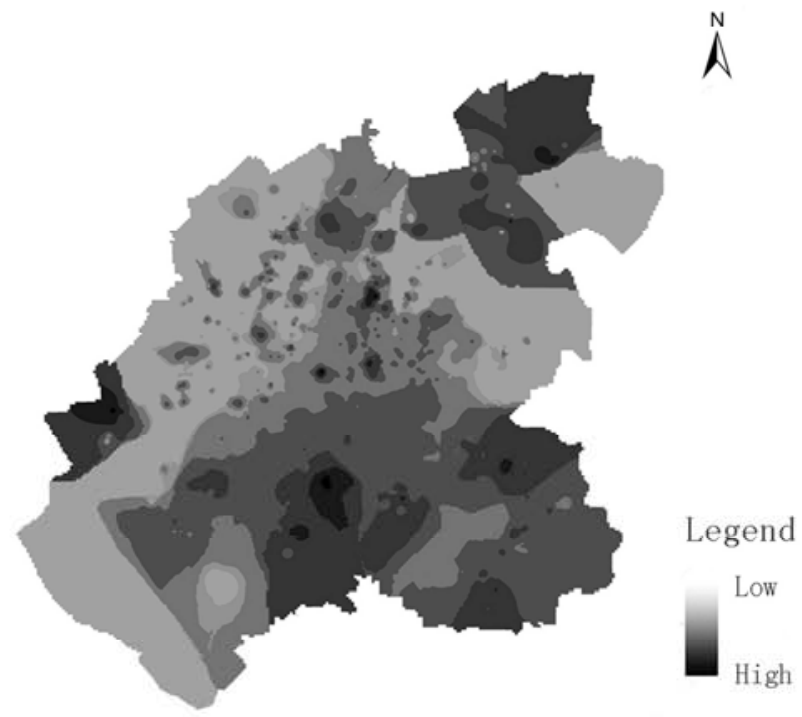

Figure 4. Analysis of accessibility of different public service facilities. 


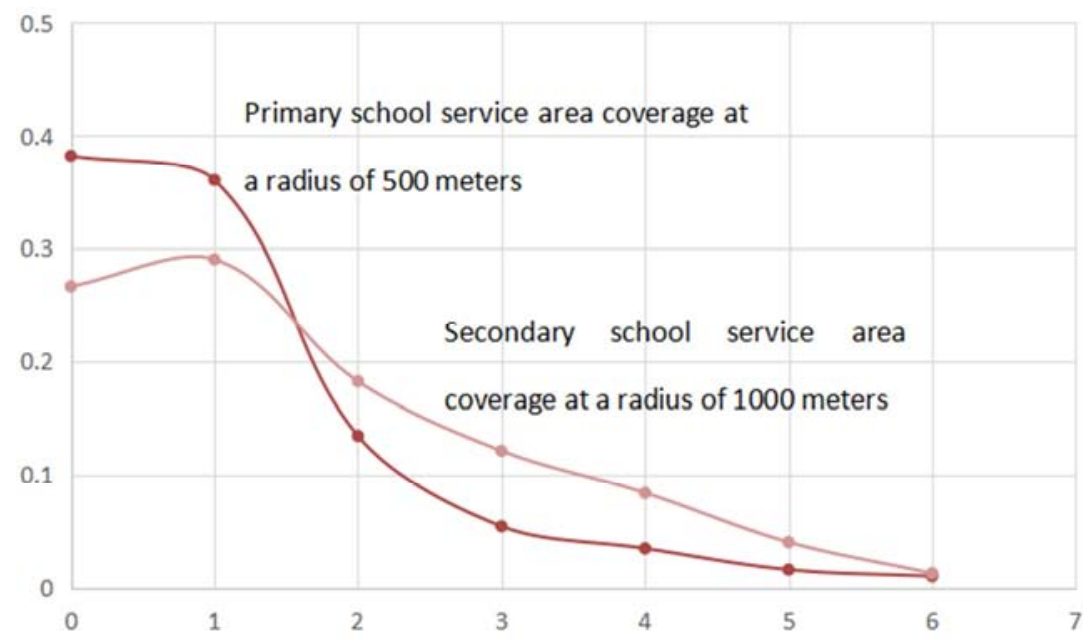

Figure 5. Coverage ratio of primary and secondary schools.

\subsection{The Relationship with Population Density}

Changchun downtown area population density

Population distribution of 10-19 years old
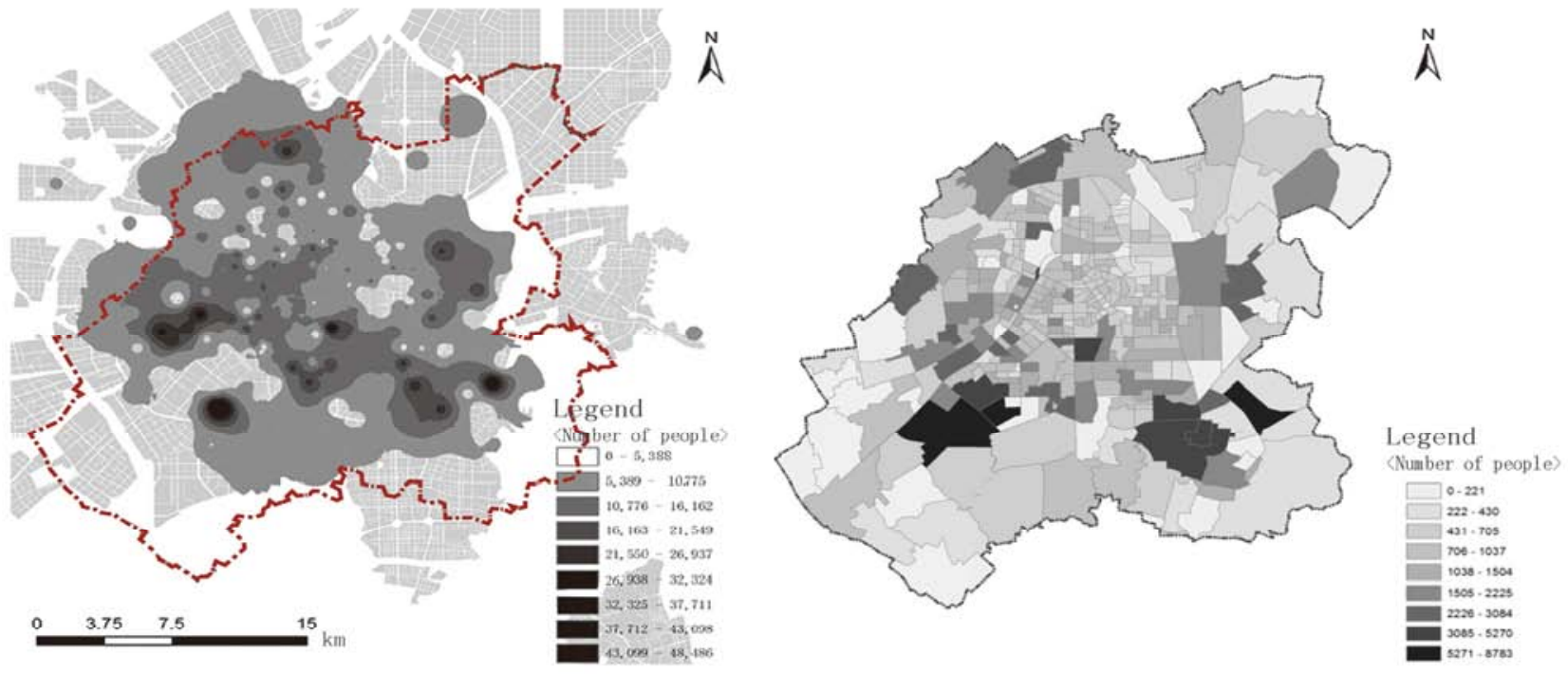

Population distribution of 20-44 years old

Population distribution over 60 years old
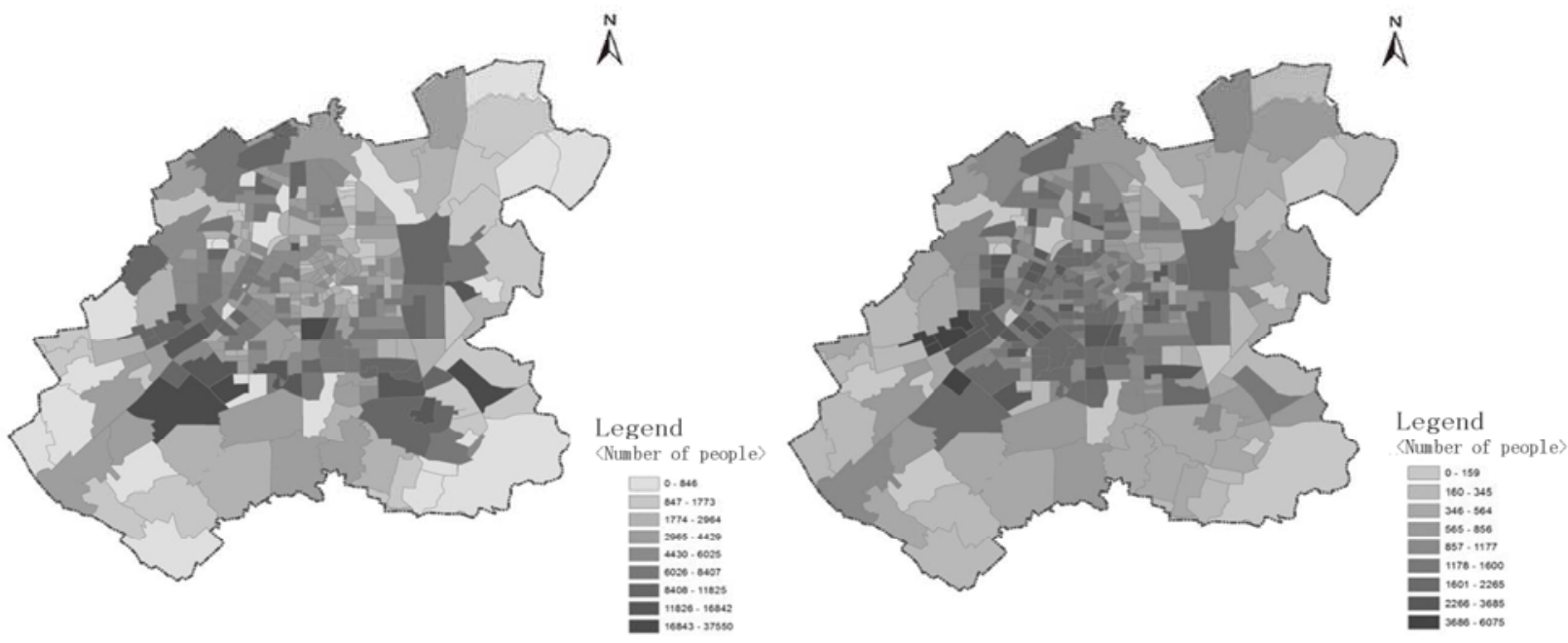

Figure 6. Population distribution in Changchun City. 
Based on the population of Changchun City Statistical Yearbook, the population of Changchun City was 7.545 million as of 2014. As shown in Figure 6, the most densely populated place in Changchun is not the traditional Chongqing Road Center, but the center of the automobile factory, and the population density of the Jingyue Center is also large. The distribution of different ages residents is also different. Here, the population distribution of adolescents, middle-aged and old age groups is taken as an example. The population aged 10-19 is concentrated in the areas where universities such as Jilin University, Changchun University of Technology, and the Jingyue University City have the highest population density. The rest of the population density is low. The distribution of the population aged 20-44 is southward, and the population of the Automobile District and Jingyue District are densely distributed. The population over 60 years old has a relatively even distribution, and the automobile city and the traditional central area are highly distributed. It can also be seen from the above analysis that the population distribution of different ages is closely related to the spatial concentration of public facilities. If the population distribution of different ages and the spatial aggregation of related public service facilities are consistent, it proves that the spatial matching degree is higher. The spatial aggregation of science, education and cultural facilities and the distribution of the population of 10-19 years old are inconsistent, indicating that the overall spatial matching of educational and cultural facilities is not high. The distribution of population over the age of 60 should be influenced by social welfare facilities. It can be seen from the figure 6 that the matching degree of the facility is high, but the area of the Automobile District needs to be improved.

\subsection{The Relationship with the Space Environment}

Encouraging citizens to walk is one of the basic requirements of a compact city, so the creation of outdoor public spaces such as parks is particularly important. From the density of population distribution in Changchun City, the difference in attractiveness of different environments can be seen. As shown in the following figure, the distribution of green areas such as parks runs through the downtown area of Changchun with the Yitong River as the axis. The most attractive ones are Nanhu Park and Jingyue Scenic Area. In recent years, Beihu has become more and more popular among the elderly.

At the same time, the construction of the walking system is also an important factor that directly affects whether residents choose outdoor sports. Based on the construction of Changchun landscape structure, the traditional six streets in Changchun City were evaluated. The spatial relationship can be seen in Figure 7. Although the walking space is generally considered in the construction of the landscape axis, the grasp of the spatial scale and the barrier-free design are undoubtedly ignored. The poorly comfortable walking system is less attractive to residents and the quality of service is greatly reduced.

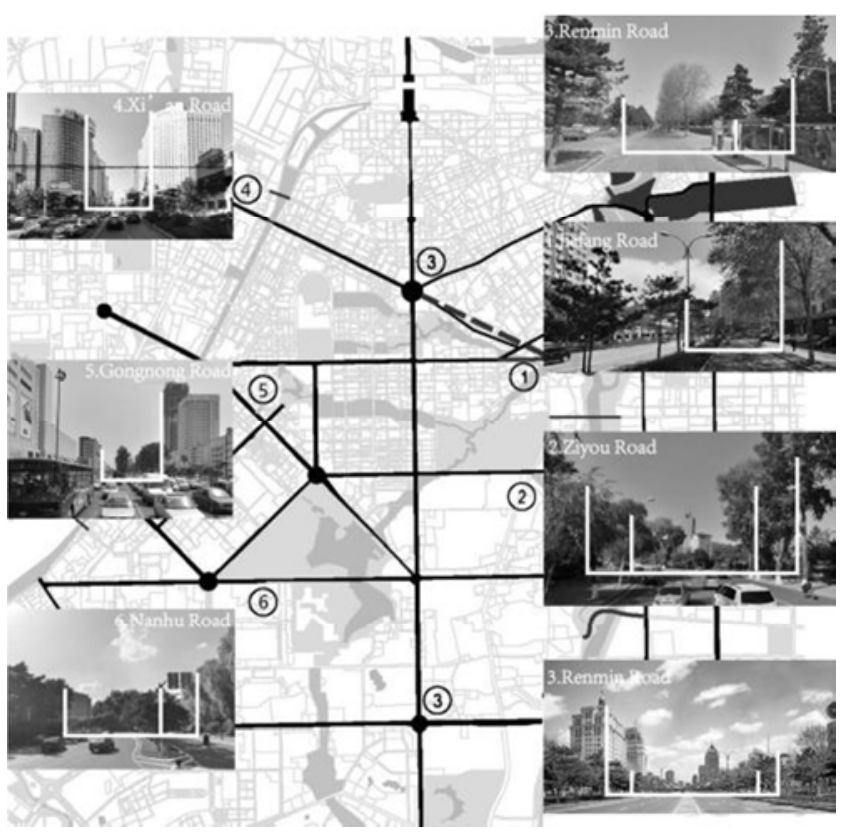

Figure 7. Landscape structure in Changchun.

\section{Analysis of Factors Affecting Space Efficiency}

The essence of service efficiency is the fairness and quality of service. Therefore, it is divided into three categories: supply factor, connection factor and demand factor in the construction of the impact system. It not only studies the ability to give services, but also considers the need to accept services, thus improving the quality of services.

\subsection{Supply Factor}

\subsubsection{Quantity and Proportion of Different Facilities}

The number of different facilities is the most intuitive to evaluate the quality of service. When meeting the accessibility, the more facilities, the more people can be served. However, the single count cannot reflect the aggregation of different functions, and the diversification of functions will attract more people, so the improvement of functions is also the embodiment of efficiency. In terms of quantity alone, Changchun City has a large number of facilities in the north, but considering the compounding of functions, Changchun City lacks sports facilities and social service facilities as a whole [19].

\subsubsection{Spatial Distribution of Different Facilities}

In general, the more facilities there are, the more people can be served, and the greater the efficiency of service. Nuclear density analysis is one of the important ways to visualize the degree of spatial aggregation. The higher the density, the more attractive it is. All kinds of public service facilities in Changchun City are concentrated in the center of Chongqing Road, and are decreasing to the periphery. So it is necessary to consider the spatial layout of the edge of the city 
center.

\subsection{Connection Factor}

\subsubsection{Traffic Accessibility}

Service efficiency is directly related to the capacity of urban roads, that is, the spatial accessibility of facilities. With the development of GIS technology, the spatial analysis method digitizes and visualizes the urban road traffic network, which improves the realism of the analysis. As the road density increases, the road aggregation degree increases, the connection degree increases, and the network structure becomes more perfect, the difficulty for users to reach the city public service facilities will be reduced, the time cost will be reduced, and the service radius and use efficiency will be improved.

\subsubsection{Land Use}

Urban land use will eventually be reflected in the urban road network. If closed management is adopted in the construction, the resistance to be overcome for pedestrians will increase, and the open space such as squares and walking paths will have relatively little resistance to pedestrians, and it can also serve to encourage residents to walk [20].

\subsection{Demand Factor}

\subsubsection{Population Distribution}

The matching degree between population and facilities is the main content of service efficiency. The distribution of population directly affects the number of users and the frequency of use of urban public service facilities. If the matching degree is low, it will cause two kinds of unfavorable phenomena such as extremely crowded comfort or waste of resources. At the same time, residents of different ages have different needs, and service efficiency should also consider the needs of the service population. Although the factors of uneven population distribution are more complicated, reasonable guidance from planning and construction can improve the imbalance of spatial allocation to some extent.

\subsubsection{Environmental Needs}

The degree of environmental friendliness is not only the needs of the residents, but also the needs of social development. The planning and design of the space environment and resource utilization is also a requirement for service quality. Therefore, responding to the call for wellness facilities from a spatial perspective is also an important factor in improving service efficiency [21].

\section{Optimization Strategy for Land Use of Public Service Facilities in Changchun City}

In the context of a compact city, the study of land use efficiency of public service facilities represents the pursuit of social justice, and is also the pursuit of functional coupling, while paying more attention to the matching of space and the construction of human settlements. This study mainly analyzed the service efficiency of public service facilities in downtown Changchun from the perspective of space matching, and studied the influencing factors that lead to these results. This can provide the following recommendations for the construction and optimization of public service facilities in Changchun:

\subsection{Macro Level - External Regional Spatial Regulation Strategy}

In the specific urban construction and development behavior, it should be clear what kind of construction and development behavior is market-led and what is dominated by policy intervention. Then, as far as possible, avoid the problems of spatial imbalance under market failure or excessive intervention under the misplacement of administrative roles, and ensure the healthy and rational development of urban space at different stages through the joint action of the two.

\subsection{Middle Level - Spatial Compactness Optimization Strategy}

\subsubsection{Compact Center Spatial Structure Construction}

First of all, the core circle needs to be effectively deconstructed. The distraction of spatial elements is not only the dispersion of population, but also the search for more growth points, and the effective deconstruction of the population through the urban function of the core area and the relief of employment positions. Secondly, we had better to pay attention to the organic combination of industrial structure and ecological function. Thirdly, for the peripheral group, the land use efficiency is inefficient and the function is not coordinated. Therefore, it is necessary to focus on improving the service functions of various facilities, adding residential and supporting land, and strengthening the land use intensity. At the same time, it is considered to further guide the effective agglomeration of various spatial elements, form a number of functional groups that are independent of the core development.

\subsubsection{Population Distribution Guidance under the Balance of Occupation}

We should try to adjust the proportion of land use through the flexible mechanism, set a reasonable proportion of living and supporting land, adhere to employment orientation, and pay attention to development guidance and project guidance. At the same time, it is necessary to highlight certain differentiated features in the function configuration of the group, and to attract population aggregation through this difference, so as to avoid the homogenization of the functions of sub-centers and groups at all levels.

\subsubsection{Improve Transportation Facilities and Road Structure Network}

By improving the network of traffic and road structures 
and the accessibility within the block, it can allow residents quickly enter or leave the block. Thereby attracting more people into the block and forming a virtuous circle.

\subsection{Micro Level - Internal Space Element Configuration Strategy}

In the construction of facilities, we will pay attention to the balance of facilities in the old and new urban areas, strengthen the construction of cultural facilities and sports facilities in Chaoyang and High-tech South District, and create an industrial model that combines culture and sports. Educational and medical resources are mainly concentrated in the old city center, and attention should be paid to the construction of educational and medical facilities of border areas .

\section{Conclusion}

This paper mainly studied the spatial configuration of public welfare public service facilities in the downtown area of Changchun. (1) In terms of quantity, the number of facilities can directly reflect the level of service. The number of POI in health care facilities is the highest and the second is the cultural and educational facilities. The number of educational and cultural facilities is getting higher and higher, and the proportion of cultural facilities and educational facilities is similar. The number of sports facilities is mainly the sum of parks and sports venues. The number of parks in Erdao District is the least, and the playground in Kuancheng District is the least. The proportion of social welfare facilities is dominated by nursing homes. Because both the Kuancheng and Lvyuan District are traditional old districts, they have the largest number of nursing homes, but the Chaoyang District, which is the most traditional urban center, has the fewest.(2) From the perspective of spatial distribution, a high density in the unit area indicates a significant spatial distribution. The nuclear density distribution of educational cultural facilities and medical care facilities in the downtown area of Changchun are similar. They are spread out in a single center centered on Chongqing Road. Sports facilities are distributed in multiple centers, and social welfare facilities are scattered. (3) As for spatial matching, the analysis was combined with facility distribution and accessibility. (4) For population demand, population density can directly reflect the interaction and attraction of different facilities.

Through the above analysis, the paper gave recommendations through macro, meso and micro three levels. In the construction of facilities, we should carefully divide the school district, equitably allocate educational resources, and at the same time control the explosive development of educational institutions, attach importance to the construction of medical community service centers to maximize medical resources. In the management mechanism, the community environmental assessment index needs to be regularly evaluated, including community health centers, slow-moving systems, human facilities, natural environment and special population services. In the development of the industry, we should pay attention to the elements of population demand, set up different types of facilities according to different ages and genders, and integrate other industries. In the design of the space environment, we need to attach importance to the construction of the walking system and the public transportation system, encourage residents to walk or have outdoor activities, create a comfortable space scale, and utilize the pocket space. In terms of lifestyle, primary and secondary schools are encouraged to study the "walking school bus" program in western countries and hold more outdoor activities for citizens in cities.

Due to the limited data resources in this paper, this research has limitations and needs further research.

\section{References}

[1] M. Jenks, E. Burton, K. Williams. The compact city: a sustainable urban form, London: Routledge, 1996.

[2] K. Williams. Urban intensification policies in England: problemsand contradictions, Land Use Policy, 3rd ed, vol. 16.1999, pp. 167-178.

[3] M. Z. Mahriyar, J. H. Rho. The compact city concept in creating resilient city and transportation system in Surabaya, Procedia-Social and Behavioral Sciences, vol. 135, 2014, pp. 41-49.

[4] M. Hong, F. J. Jin. Ideology and the implication of land use in a compact city, China Land Science, 7rd ed, vol. 24.2010, pp. $10-13,29$.

[5] L. Li, X. P. Huang. The Research on compactness based on analyzing the meaning of "compact": constructing the system of concepts and indexes for "compactness", Urban Planning International, 1st ed, wol. 27, 2012, pp. 33-43.

[6] Y. P. Wei, M. Zhao, J. B. WANG. Compact development \& land use performance measurements: an applicable expansion of "Thunen - Alonso" model, Urban Planning Forum, 3rd ed, 2008, pp. 32-40.

[7] M. B. Teitz. Toward a theory of public facility location. Papers of the Regional Science Association, 1st ed, vol. 21, 1968, pp. 35-51.

[8] R. Rich. Neglected issues in the study of urban service distribution: A research agenda. Urban Studies, 2nd ed, vol. 16, 1979, pp.143-156.

[9] R. Lineberry. Equality and Urban Policy: The Distribution of Municipal Public Service. Beverly Hills, CA: Sage, 1977.

[10] G. DeVerteuil. Reconsidering the legacy of urban public facility location theory in human geography. Progress in Human Geography, 1st ed, vol. 24, 2000, pp. 47-69.

[11] Y. Ding. Fotheringham A S. The integration of spatial analysis and GIS. Computers, Environment and Urban Systems, 1st ed, vol. 16, 1992, pp. 3-19.

[12] J. Pickles. Tool or science? GIS, technoscience, and the theoretical turn. Annals of the Association of American Geographers, 2nd ed, vol. 87, 1997, pp. 363-372.

[13] T. Neutens, T. Schwanen, F. Witlox, et al. Social equity of public service delivery: A comparison of different accessibility measures. Environment and Planning A, 7rd ed, vol. 42, 2010, pp. 1613-1615. 
[14] R. Miranda, I. Tunyavong. Patterned inequality? Reexamining the role of distributive politics in urban service delivery. Urban Affairs a Quarterly, 4rd ed, vol. 29, 1994, pp. 509-534.

[15] E. Talen. Visualizing fairness: Equity maps for planners. Journal of the American Planning Association, 1st ed, vol. 64, 1998 , pp. 22-38.

[16] W. G. Hansen. How Accessibility Shapes Land Use. Journal of the American Institute of Planners, 2nd ed, vol. 25, 1959, pp. 73-76.

[17] S. L. Handy, D. A. Niemeier, S. L. Handy, et al. Measuring Accessibility: an Exploration of Issues and Alternatives. Environment \& Planning A, 7th ed, vol. 29, 1997, pp. $1175-1194$

[18] T. Neutens, T. Schwanen. F. Witlox, et al. Social equity of public service delivery: A comparison of different accessibility measures. Environment and Planning A, 7th ed, vol. 42, 2010, pp. 1613-1615.

[19] X. P. Wang, P. Hu, S. S. Shen, et al. Spatial characters of public service facilities from social differentiation viewpoint. Planners, 5th ed, vol. 30, 2014, pp. 17-24.

[20] Y. Tan, C. Pi, D. J. He, et al. Spatial characteristics and their causes of the urban and rural public service facilities in Guangzhou. Tropical Geography, 2nd ed, vol. 34, 2014, pp. 241-247.

[21] M. Apaydin, A. Singh, D. Brutlag, and J.-C. Latombe, "Capturing molecular energy landscapes with probabilistic conformational roadmaps," inProc. IEEE Int. Conf. Robot. Autom., 2001, pp. 932-939. 